\title{
Express test for the simultaneous diagnosis of encountering PAMG-1 and PAMG - 2 using technique of immune chromatography using nanozolota and IPMS-ELISA using isotopes Eи3+ and Sm3+
}

Zaraisky E. I. IPRIM RAS, Moscow

Summary: the simultaneous determination of PAMG-1 and PAMG -2 in blood serum by enzyme immunoassay(and PMS-ELISA) based on inductively coupled plasma mass spectrometry (IPMS-ELISA) and immunochromatographic analysis was studied. The PAMG-1 and PAMG-2 measurement ranges were 1$100 \mathrm{ng} / \mathrm{ml}$, respectively, with detection limits I ( 3 SD above the mean of the zero calibrator), respectively. Compare and PMS-OLD ECHO for PAMG- 1 and PAMG - 2 have correlation coefficients ( $r 2$ ) of 0.97 and 0.95. Thus, it is shown that both methods allow to measure two proteins with comparable accuracy.

Key words: ELISA, PAMG-1, PAMG-2, Ei3+, Sm3+, immunochromatography

Simultaneous multianalysis of several analytes is important for solving a wide range of biological and medical problems, including for screening diagnosis of cancer pathology. The use of conjugates of gold nanoparticles, quantum dots and other achievements of nanotechnology in recent years can effectively solve the problem of multianalysis. For these goals, developing hybrid methods, including ELISA, radioanalyt, differential counting multimeter. Such analysis, for example, is the IPMS-ELISA method [1,2]

Materials and methods

PAMG-1 and PAMG-2, and monoclonal mouse antibodies against them were obtained from Nano-lab LLC, Russia. We used deionized water with a resistance of $18 \mathrm{MW}$ for all experiments. N" - [pisothiocyanatobenzyl] - diethylene-triamine- $\mathrm{H} 1, \mathrm{H} 2, \quad \mathrm{~N} 3, \quad \mathrm{~N} 3$-tetraacetate europium and $\mathrm{N}$ - $[\mathrm{p}-$ isothiocyanato-benzyl]-monoethylene glycol - triamine- $\mathrm{H} 1, \mathrm{H} 2, \mathrm{~N} 3, \mathrm{~N} 3$-samarium tetraacetate are obtained from Tianjin radio Engineering Medical Institute. 96-well stripped dies were obtained from NUNC Co. The following buffers were used-Covering-100 mmol/l carbonate $(\mathrm{pH} 9.5)$, containing $9 \mathrm{~g} / \mathrm{I} \mathrm{NaCl}$ and $0.4 \mathrm{~g} /$ I NaN3;Blocking, containing $50 \mathrm{mmol} / \mathrm{I}$ Tris- $\mathrm{HCl}(\mathrm{pH} 7.0)$ ), containing $9 \mathrm{~g} / \mathrm{I} \mathrm{NaCl}$ and $0.4 \mathrm{~g} / \mathrm{I} \mathrm{NaN3}$;and $10 \mathrm{~g} / \mathrm{l}$ bovine serum albumin, analytical, containing $50 \mathrm{mmol} / \mathrm{l}$ Tris HCl $(\mathrm{pH} 7.8)$, containing $20 \mathrm{~g} / \mathrm{l}$ bovine serum albumin, $0,4 \mathrm{~g} / \mathrm{I} \mathrm{NaN3}, 9 \mathrm{~g} / \mathrm{I} \mathrm{NaCl}$, and $0.4 \mathrm{ml} / \mathrm{I}$ Tween 20, washing buffer $50 \mathrm{mmol} / \mathrm{I} \mathrm{Tris}-\mathrm{HCl}(\mathrm{pH} 7.4)$, containing $0.4 \mathrm{~g} / \mathrm{I} \mathrm{NaN3}, 9 \mathrm{~g} / \mathrm{l} \mathrm{NaCl}$, and $0.4 \mathrm{ml} / \mathrm{I}$ Tween 20. Conjugates of the monoclonal antibody-PAMG1 and PAMG -2 with nanogold $30 \mathrm{~nm}$ obtained from the company Nano-lab.

Antibodies against HCG and AFP were labeled with ei3+ and Sm3+ chelates, respectively.

For this, $1 \mathrm{~g} / \mathrm{I}$ antibodies in $50 \mathrm{mmol} / \mathrm{I}$ carbonate buffer (pH9.5) were mixed with $0.35 \mathrm{mg}$ Ei3+ and $\mathrm{Sm} 3+$ chelate complexes and incubated at $4{ }^{\circ} \mathrm{C}$ overnight. Chelate-bound antibodies were purified from unbound reagents on the Sephadex g-25 column $(1.525 \mathrm{~cm})$ and eluted with a $50 \mathrm{mmol} / \mathrm{l}$ Tris- Hcl buffer ( $\mathrm{pH} 7.0)$ containing $9 \mathrm{~g} / \mathrm{l}-7$ -

$\mathrm{NaCl}$ and $0.5 \mathrm{~g} / \mathrm{I} \mathrm{NaN3}$. The concentration of Ei3+ was determined by comparison with the calibrator.

The concentration Еиз+ labeled anti - PAMG-1 and PAMG - 2 monoclonal[ antibodies

calculated by the formula)

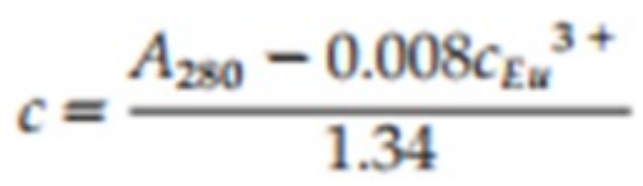


Where with A280 absorption of Ei3+ - labeled anti-PAMG-1 and PAMG -2 antibodies at $280 \mathrm{Nm}$, 1.34 is the optical density of $1 \mathrm{~g} / \mathrm{l}$ EC3-labeled anti-AFP monoclonal antibodies at $280 \mathrm{Nm}$, and 0.008 is the absorption coefficient of $1 \mathrm{~mol} / / \mathrm{EC} 3$ chelate at $280 \mathrm{Nm}$. The yield of the conjugation were obtained by calculating ratio of concentration of Labelled Еи3+ monoclonal antibodies of AFP concentration Еи3+ in solution. Similarly, the yield of conjugation of Sm3-labeled antibody to HCG monoclonal antibodies was calculated. One mole of anti-AFP antibodies was labeled with 7.1 mole of Ei3+ chelate, while 1 mole of antiHCG antibodies was labeled with 12.3 moles Of $\mathrm{sm} 3 \mathrm{~cm} 3$ chelate. Standard concentrations of Ei3+ and Sm3+, (5 g / L) and optimal key settings of ICP-MS equipment were selected for optimal analysis.The dependence of the signal intensities $\mathrm{Ei} 3+$ and $\mathrm{Sm} 3+$, were investigated in the argon flow at flow rates of 0.7-1.1 I/ min. Ei3+ and Sm3+, behaved similarly giving a total peak at $1 \mathrm{I} / \mathrm{min}$ (Fig. 1). The maximum intensity of Ei3+ was twice as high as $\mathrm{Sm3}+,(52.2 \%$ for Ei3+ and $26.7 \%$ for $\mathrm{Sm} 3+)$.

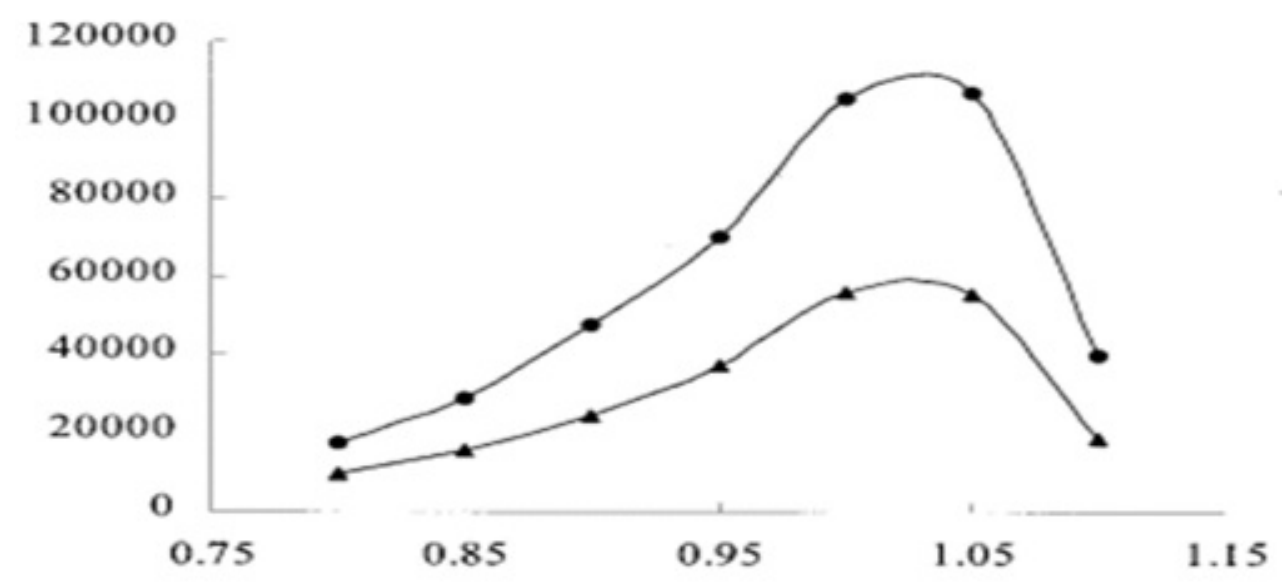

Fig 1. Optimization of argon flow to analyze IPMS-ELISA On the $x$-axis shows the flow of argon(I/ $\min )$ On the ordinate axis-the power radiation of the isotope.Concentration of Ei3+ and $\mathrm{Sm3}+, 5 \mathrm{~g} / \mathrm{I}$, current power $1250 \mathrm{~W}$, voltage $8 \mathrm{~V}$

Two definitions were performed for each sample. Analytical results are obtained by calculating the average of two definitions of each sample. The ratio is calculated by the linear least squares method according to the criterion

Student. The calibration curves for IPMS-IFA are shown in Fig.2

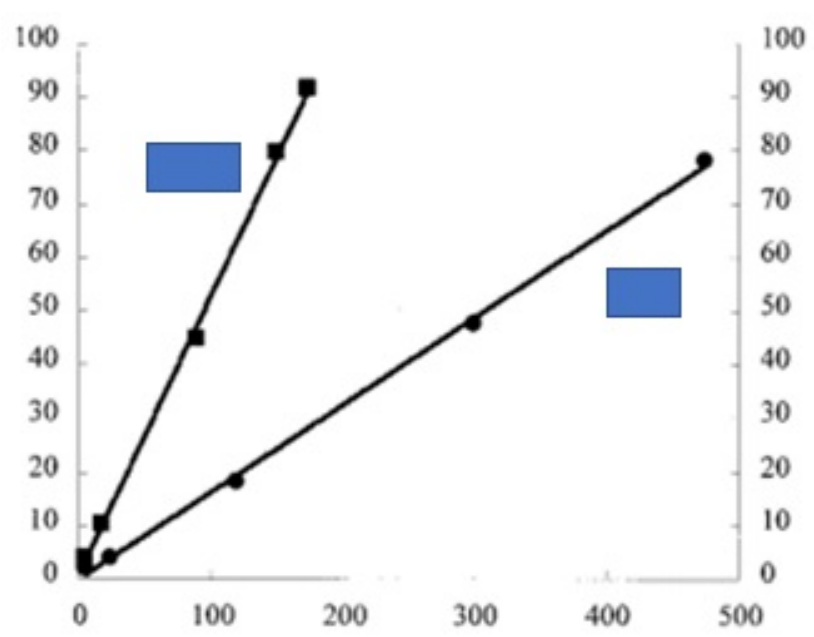

Fig.2 Calibration curve for concentration determination

conjugates along the abscissa axis of concentration of PAMG-1 and PAMG-2 in $\mathrm{ng} / \mathrm{ml}$.

On the ordinate axis the ratio of signals is $(52 \mathrm{Sml} 174 \mathrm{Yb}) \%$

Blood samples were taken from 20 patients of a network of clinics "Family doctor"(Moscow, Russian Federation.) after obtaining informed consent from patients. Serum was obtained as previously described [3] 
serum Samples were then stored at $20^{\circ} \mathrm{C}$ under nitrogen gas prior to use

IPMS-ELISA was performed according to the standard procedure for ELISA [3], the complex MAT PAMG-1 and Ei3+ and PAMG - 2 with Sm3+ were used as conjugates. After washing from unbound conjugates, the label was washed with a solution of HNO3 $(10 \mathrm{ml} / \mathrm{l})$ and delivered to the mass spectrometer by a peristaltic pump. The analysis was performed after optimization of the reaction

Calibration Cree PAMG-1 and PAMG-2 Vaya and sensitivity analysis are shown in Fig.2 simultaneous determination of PAMG-1 and was in the concentration range 4.6-500 ng $/ \mathrm{ml}$, and for PAMG-2 $\mathrm{ng} / \mathrm{ml}$. regression Equations for calibration curves were: $\mathrm{l}=0.16 \mathrm{C}+0.06$ for $\mathrm{AFP}(\mathrm{r}=0.9984)$ and

$\mathrm{I}=0.52 \mathrm{C}+0.96$ for $\mathrm{PAMG}-1 \quad(\mathrm{R} 2=0.9987)$, where $\mathrm{I}$ is the relative signal intensity and $\mathrm{C}$ is the concentration.The lower limit was determined as 3SD lower than the mean of 12 measurements and was 1.2 $\mu \mathrm{gl}$ for PAMG-1 $1.7 \mu \mathrm{gl}$ for PAMG-2 IHA for the two antigens was performed as previously described [3] as kongugatov used conjugates of the MAT against AFP and beta HCG, labeled with nanogold particle size of $30 \mathrm{~nm}$. The results were taken into account on the hardware-sof tware complex "Expert-lab".

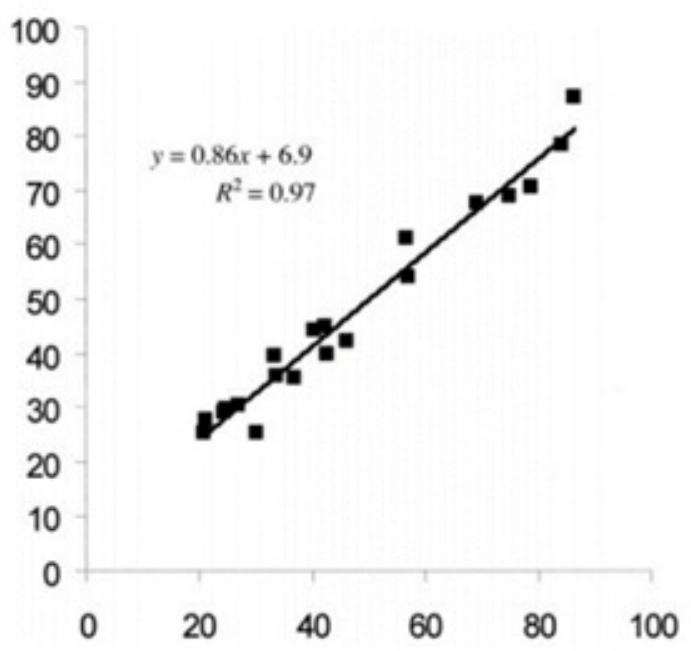

Fig3 the relationship between the results of determining the concentrations of the two encountering in the sera of patients containing PAMG-1 and PAMG - 2 methods ELISAn IPMS-ELISA for PAMG- 1 and PAMG-2. On the ordinate axis, AND on the abscissa axis, the results of IPMS-ELISA Showed that the relationship between the results of determining the concentrations of two oncoantigens in the serum of patients containing PAMG-1 and PAMG-2 the methods of ICA and IPMS-ELISA is very high and practically insignificant, which of these methods is used for diagnosis. The advantage of IPMS-ELISA is its high potential for automation, faster than traditional ELISA execution at a relative cheapness[4,5]. The disadvantage of the method is the work with radioactive isotopes, which is often organizationally difficult due to environmental insecurity. On the other hand, IHA is faster, not more expensive, but less amenable to automation. Thus, for the screening of large arrays of samples, IPMS-IFA is preferable, and for home screening of IHA.

\section{List of references}

1 D Scott Tanner, Vladimir Baranov, Dmitry Bandura Spectrochimica Acta Part B: Atomic spectroscopy Review Reaction cells and collision cells for ICP-MS: a tutorial review:

Atomic Spectroscopy 57: 9: September 2002 1361-1452

httpsedoi.org/10.1016/S0584-8547 (02)00069-1

2 Sichun Zhang, Chao Zhang, Zhi Xing, and Xinrong Zhang Simultaneous Determination of-Fetoprotein andF

1214-1221 (2004)

3 Zaraisky E. I., Poltavtsev A. M., Osmak G. J., Ogulina G. N., R. A. Poltavtsev 
Three-zone biosensor for rapid diagnosis of cancer and male infertility on the basis of nanozolot conjugates with monoclonal antibodies to placental protein glycodelin, Nanotechnology and health, 6: 4 18-24 (2014)

4 Akulenko I.V.,Nazimova S.V., Boltovskaya M.N., Starosvetskaya N.A., ZaraiskyE. I. // New method of endometriosis diagnostic alpha-1- microglobulin (PAMF-1).Abstr. XVIIIth Meeting of ISOBM, Moskow, September, 1990. - P. 30.

5 Nazimova S.V., Pchelkina Z.M., Boltovskaya M.N., Starosvetskaya N.A., ZaraiskyE. I. // A novel elisa kit based on monoclonal anti-bodies for quantitation of placenta-specific alpha-1-microglobulin (PAMG-1) Immunology of reproduction, Kiev, 1990. - P. 85. 